\title{
In vitro clonal propagation, organogenesis and somatic embryogenesis in Bacopa monnieri (L.) Wettst
}

\author{
Dipu Samanta ${ }^{1}$, Bidisha Mallick ${ }^{2} \&$ Debleena Roy $^{2^{*}}$ \\ ${ }^{1}$ Department of Botany, Dr. Kanailal Bhattacharyya College, Ramrajatala, Howrah 711 104, India \\ ${ }^{2}$ Department of Botany, Lady Brabourne College, P-1/2, Surahwardy Avenue, Kolkata 700 017, India
}

\section{Article history}

Received: 24 June 2019

Accepted: 02 August 2019

Published: 01 October 2019

\section{Guest Editor}

Dr Nishikant Wase

\section{Publisher}

Horizon e-Publishing Group

*Correspondence
Debleena Roy
$\square$ debleenaroy@rediffmail.com

\begin{abstract}
Bacopa monnieri (L.) Wettst is a well-known medicinal herb in the Ayurveda. It is also used as laxative and curative for ulcers, inflammation, anaemia, scabies, leucoderma, asthma and epilepsy, enlargement of spleen, leprosy and others. In vitro propagation and regeneration through somatic embryogenesis of $B$. monnieri has played an important role in the production of healthy, disease-free plants with desirable traits. In B. monnieri, there are few reports which indicate rapid regeneration and somatic embryogenesis. For in vitro clonal propagation, the highest shoot formation was obtained when BAP $2 \mathrm{mg} / \mathrm{l}$ used. The best response for rooting was obtained in IAA $1.0 \mathrm{mg} / \mathrm{l}$. The recorded survival rate of the plants was $70 \%$. Plants were without any detectable phenotypic variations. Cytological study indicated that the chromosome number remain same $(2 n=64)$ in in vitro and in vivo roots. A rapid, simple and efficient protocol for plantlet regeneration was achieved through embryogenic callus from leaf explants of $B$. monnieri. Callus induction and embryogenesis were significantly affected by presence/absence and type and concentration of growth regulators. Best organogenic callus induction was obtained in MS medium supplemented with BAP $5 \mathrm{mg} / \mathrm{l}$. For induction of somatic embryogenesis, auxin (2, 4-D $1 \mathrm{mg} / \mathrm{l})$ was used in the culture medium subsequently in basal media for embryo maturation. $\mathrm{Kn} 0.2 \mathrm{mg} / \mathrm{l}$ was the best for production of plantlet from embryo. Thus, this can be an easiest protocol for stable clonal propagation and plant regeneration through somatic embryogenesis in $B$. monnieri. The protocol used here for propagation and regeneration is much easier, low cost and reliable.
\end{abstract}

Keywords: Bacopa monnieri; in vitro; Organogenesis; Rooting; Shoot Bud Multiplication; Somatic Embryogenesis

Citation: Samanta D, Mallick B, Roy D. In vitro clonal propagation, organogenesis and somatic embryogenesis in Bacopa monnieri (L.) Wettst. Plant Science Today 2019;6(4):442-449. https:/l doi.org/10.14719/pst.2019.6.4.600

Copyright: (c) Samanta et al (2019). This is an open-access article distributed under the terms of the Creative Commons Attribution License, which permits unrestricted use, distribution, and reproduction in any medium, provided the original author and source are credited (https://creativecommons.org/licenses/by/4.0/).

Indexing: Plant Science Today is covered by Scopus, Web of Science, BIOSIS Previews, ESCI, CAS, AGRIS, CABI, Google Scholar, etc. Full list at http://www.plantsciencetoday.online

\section{Introduction}

Bacopa monnieri (L.) Wettst. (Scrophulariaceae) is a well-known medicinal herb in the Ayurveda. The International Union for Conservation of Natural and National Resources has a long time ago listed Bacopa monnieri as a threatened species but at present Bacopa monnieri comes under Least Concern Category (1). The plant is commonly known as "Brahmi" and found as spreading herbs. 
Multiple branches form a mat like structure if they are growing on hard surface. Small roots are produced from each node. White flowers can be seen in well grown plants during rainy season. It is also known as the Indian water hyssop. The plant is commonly found in wet, damp and marshy areas and is widely distributed throughout India, Nepal, Sri Lanka, China, Taiwan, Vietnam and is also found in Florida, Hawaii and other southern states of the USA where it can be grown in damp conditions by the pond or bog garden (2). This plant is used as a brain tonic, which is effective in maintaining vigour and intellect. It enhances the efficiency of transmission of nerve impulses by strengthening memory and cognition (3). It is also used as laxative and curative for ulcers, inflammation, anemia, scabies, leukoderma, asthma and epilepsy, enlargement of spleen, leprosy, eczema, rheumatism, insanity and snake bite, appetitive and cardiotonic (4). B. monnieri has been considered as the most important Indian medicinal plants evaluated on the basis of medicinal importance, commercial value and potential for further research and development (5). Bacopa monnieri has been used for centuries as a brain tonic, memory enhancer, revitalizer of sensory organs, anti-anxiety, cardio-tonic, diuretic; antidepressant and anticonvulsant agent was seen by some workers (6). In India and Pakistan, the plant is also used for all sorts of skin problems like eczema, psoriasis, abscess, ulcerations, leprosy, for chronic rheumatism as an ointment, asthma and hoarseness of the voice (7).

The herb requirement is rising rapidly in view of the popularity of the $B$. monnieri based drugs (7). In view of wider market demand, there is need to conserve the wild stocks of $B$. monnieri. Due to progressively increasing demand, more than $90 \%$ of plant species used by industry are collected from the wild source of which $70 \%$ involves unorganized harvesting, leading to rapid depletion of the plant. It also needs immediate conservation and also to meet the growing demand of raw material of medicinal plants.

Tissue culture techniques may be used as alternative methods for propagation and the conservation of germplasm of this important and threatened medicinal plant in many countries. Micropropagation technique provides new possibilities for in vitro propagation and multiplication of plants and also recognized as an efficient tool for rapid clonal propagation (8). Till date a few reports are available on stable in vitro clonal propagation and somatic embryogenesis of Bacopa monnieri. Most of the work has been carried on plant regeneration by adventitious organogenesis from shoot tip, leaf and other parts of the plant. Different author worked on the micropropagation of $B$. monnieri to view the effect of auxins (IAA, NAA \& 2,4-D) and cytokinins (BAP, Kn \& TDZ) on shoot induction and IAA and TDZ on root induction (8). They also found induction of callus on Murashige and Skoog's medium (9) supplemented with NAA, 2,4-D and TDZ at various combinations and concentrations of plant growth regulators.

Work on somatic embryogenesis of $B$. monnieri, has not been done much (10). Earlier investigator cultured stem, leaf and flower bud explants in vitro for the regeneration of plantlets (11). A high frequency of embryoids (35 embryoids/ culture tube) after the transfer of nodular, leaf-derived callus onto MS medium supplemented with 2,4-D.

However, no reports are so far available on stability of the regenerates; in the study the stability of regenerated plants was verified at cytological level. The present investigation provides an important documentation about in vitro propagation and regeneration through somatic embryogenesis.

\section{Materials and Methods}

\section{Materials}

Healthy, young and disease free Bacopa monnieri plants were procured from the Medicinal Garden of the Botany Department of the Lady Brabourne College, Kolkata, West Bengal. The plants were identified by the experts of Calcutta University Herbarium (CUH), Kolkata (Fig. 1 a) and herbarium specimen was deposited at $\mathrm{CUH}$, Kolkata (Acc No. 20041).

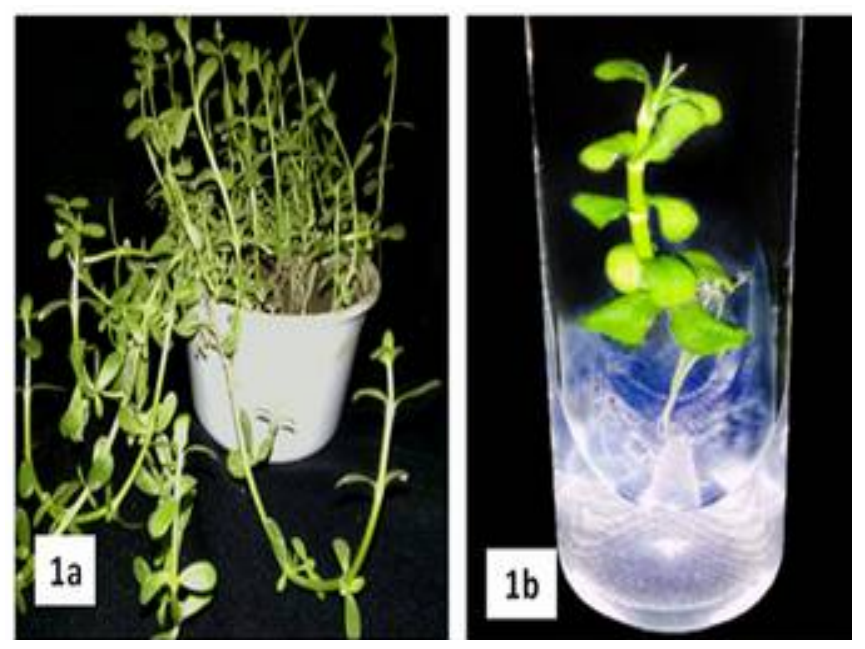

Fig. 1. a. In vivo Bacopa plant, b. In vitro Bacopa plant $($ ca $\times 1)$

\section{Establishment of culture of Bacopa monnieri- surface sterilization of explant}

Explants (apical or axillary bud, internode and leaves) were washed under running tap water for about 25 minutes, then washed with the surfactant Tween 20 solution (2-6 drops in $100 \mathrm{ml}$ solution) for 15 minutes to 20 minutes and finally rinsed with water till the surfactant was thoroughly removed. Further treatments were carried out inside a laminar air flow cabinet. The explants 
(apical bud, axillary bud, node and internode) were surface sterilized with $0.1 \%(\mathrm{w} / \mathrm{v})$ aqueous solution of Mercuric Chloride $\left(\mathrm{HgCl}_{2}\right)$ for about 10-12 minutes and then thoroughly washed with sterile double distilled water for about 10 minutes (12). Sterilized explants were cultured on MS medium supplemented with different concentrations of hormone.

\section{Culture medium}

Explants (apical bud, axillary bud, node and internode) were inoculated on MS medium supplemented with different hormone concentrations for shoot bud multiplication, rooting, callus induction and somatic embryogenesis. The $\mathrm{pH}$ of the medium was fine adjusted to 5.7-5.8 before autoclaving. Media contained 3\%(w/v) sucrose and solidified with Gelrite $0.25 \%$ (w/v) (12). Molten medium was dispensed $20 \mathrm{ml}$ (approximately) into each culture tube $(25 \times 150 \mathrm{~mm})$ and plugged with nonabsorbent cotton. The medium was autoclaved at $15 \mathrm{lbs} / \mathrm{sq}$ inch pressure and $121^{\circ} \mathrm{C}$ for 15 minutes.

\section{Culture conditions}

All the cultures were maintained at $23 \pm 2^{\circ} \mathrm{C}$ temperature and $60-70 \%$ relative humidity, photoperiod of 16 hours day light and 8 hours dark having 3000 lux light intensity by cool white fluorescent tubes (Philips India Ltd.).

\section{Shoot bud multiplication}

Shoot multiplication of Bacopa monnieri is based on medium supplemented with cytokinin as the major PGR. For shoot bud multiplication, apical or axillary buds were used (13). Explants were cultured in MS media supplemented with BAP (1$4 \mathrm{mg} / \mathrm{l})$ and $\mathrm{Kn}$ (1- $4 \mathrm{mg} / \mathrm{l})$.

\section{Root induction of microshoots}

Shoot buds were transferred to MS medium containing different concentrations of IAA (0.25$2.00 \mathrm{mg} / \mathrm{l})(\mathrm{pH}-5.8)$ for root development.

\section{Acclimatization}

Rooted plantlets were removed from the culture medium followed by washing under running tap water to remove Gelrite ${ }^{\circledR}$. Then, the plantlets were transferred to pot containing pre- soaked vermiculite and maintained inside a growth chamber set at $27^{\circ} \mathrm{C}$ and $70-80 \%$ relative humidity. After 25 days they were transplanted to poly bags containing mixture of soil + sand + manure in 1: 1: 1 ratio and kept under shade house for a period of three weeks and subsequently established in the field conditions.

\section{Induction of callus culture}

For callus induction leaves, node and internodes were used. Explants were cultured in MS media supplemented with: 1-5 mg/ 1 2, 4-D and 1-5 mg/ 1 BAP.

\section{Organogenesis}

For organogenesis, calli were transferred to MS basal media without any hormone (pH 5.7).

\section{Somatic Embryo induction}

The embryo induction medium was supplemented with of 2, 4-D (1 mg/ l) for embryo induction followed by subculture in MS basal media for embryo maturation.

\section{Plantlet formation from Somatic embryos}

The plantlets formation medium was supplemented with $\mathrm{Kn} 0.2 \mathrm{mg} / \mathrm{l}$ (pH 5.7).

\section{SEM analysis}

Samples were collected and washed twice with PBS, followed by fixing with $2.5 \%$ gluteraldehyde solution for $2 \mathrm{hr}$. The samples were dehydrated with sequential alcoholic treatment for 10 minute each and imagined using a scanning electron microscope.

\section{Determination of chromosomal stability}

Chromosome analysis involved somatic chromosome number determination from both in vivo and in vitro roots of Bacopa by propionicorcein technique (14).

\section{Data and statistical analysis}

In all the cultures, visual observations were recorded such as nodal shoot proliferation, shoot number per explants, length of the regenerated shoots, root number per explants and average root length. Each experiment comprised of 10 replicates and each experiment was repeated thrice. Mean as well as standard error were calculated. The one-way analysis of variance (ANOVA) was carried out to detect the significance of differences among the treatment means. Dunn Kruskal-Wallis multiple comparison test was followed for analysis of different hormonal treatment in case of shoot bud multiplication. Here, $p$-values adjusted with the BenjaminiHochberg method.

\section{Results and Discussion}

\section{In vitro multiplication from apical and axillary bud}

Bud breaking was found after 11 days of culture initiation. The highest percentage of multiple shoot induction was $80 \%$ on the medium augmented with $2.0 \mathrm{mg} \mathrm{l}^{-1}$ BAP (Fig. 1 b) followed by $70.00 \%$ on the medium containing $1.0 \mathrm{mgl}^{-1} \mathrm{BAP}$ and $3.0 \mathrm{mgl}^{-1}$ BAP but the number of shoot bud varied in these 2 hormones (Table 1). Lowest percentage of multiple shoots induction was found to be only $20.00 \%$ on the medium containing $1.0 \mathrm{mgl}^{-1} \mathrm{Kn}$. The highest number of shoots per apical or axillary buds was obtained on the medium having $2.0 \mathrm{mg} \mathrm{l}^{-1} \mathrm{BAP}$ followed by the medium fortified with $1.0 \mathrm{mgl}^{-1}$ BAP. On the other hand, the minimum numbers of 
shoots per explant were obtained in the medium supplemented with $1.0 \mathrm{mgl}^{-1} \mathrm{Kn}$. So, BAP $2 \mathrm{mg} / \mathrm{l}$ was the best hormone for Bacopa in respect to percentage of shoot bud formation and number of bud formation per explants (15). Statistical analysis showed that the growth regulators differ significantly among themselves with respect to type and concentration for in vitro multiplication (Table 1). Micropropagation of Bacopa monnieri indicated that it is feasible for rapid propagation, faster introduction of new cultivars with desirable traits and for rapid multiplication of disease-free, healthy propagation material. The efficacy of shoot multiplication is influenced by several factors, such as genotype, media composition, in vitro environmental factors, PGR etc. Shoot multiplication depends on the initiation and activity of meristems which are hormonally controlled mainly by cytokinin (16).

Table 1. Effects of different concentrations of BAP and Kn for shoot bud multiplication (after 20 days of culture)

\begin{tabular}{lcrr}
\hline $\begin{array}{l}\text { Growth regulators } \\
(\mathrm{mg} / \mathrm{l})\end{array}$ & $\begin{array}{l}\text { \% of shoot } \\
\text { formation }\end{array}$ & $\begin{array}{l}\text { No of shoot } \\
\text { developed/apical } \\
\text { or axillary bud* }\end{array}$ & $\begin{array}{l}\text { Shoot } \\
\text { length } \\
\text { (mm) }\end{array}$ \\
\hline BAP 1.0 & 70 & $9-13$ & $12 \pm 0.45$ \\
\hline BAP 2.0 & 80 & $12-17$ & $20 \pm 0.13$ \\
\hline BAP 3.0 & 70 & $7-12$ & $16 \pm 0.19$ \\
\hline BAP 4.0 & 60 & $4-9$ & $15 \pm 0.87$ \\
\hline Kn 1.0 & 20 & $2-3$ & $10 \pm 0.51$ \\
\hline Kn 2.0 & 30 & $7-9$ & $12 \pm 0.45$ \\
\hline Kn 3.0 & 30 & $4-5$ & $14 \pm 0.13$ \\
\hline Kn 4.0 & 30 & $4-5$ & $14 \pm 0.12$ \\
\hline
\end{tabular}

*Explant= apical and axillary bud.

**Data represents Mean \pm SE of 10 replicates.

Table 4. Response of callus for induction of somatic embryo (after 21 days of culture)

Growth regulators (mg/l) No. of embryo found/ culture

\begin{tabular}{cc} 
& tube \\
\hline 2,4-D 0.25 & 21 \\
\hline 2,4-D 0.50 & 25 \\
\hline 2,4-D 1.00 & 35 \\
\hline 2,4-D 1.50 & 30 \\
\hline 2,4-D 2.00 & 28 \\
\hline IAA 0.25 & 07 \\
\hline IAA 0.50 & 10 \\
\hline IAA 1.00 & 11 \\
\hline IAA 1.50 & 15 \\
\hline IAA 2.00 & 15
\end{tabular}

Note: To test if the growth regulators for shoot (different concentrations of BAP, Kn) differ significantly among themselves HO: The growth regulators for shoot formation do not differ significantly among themselves, H1: The growth regulators differ significantly among themselves. Kruskal- Wallis rank sum test was carried out and the $p$-value was $<0.05$, therefore we rejected $\mathrm{HO}$ and concluded that the growth regulators differed significantly among themselves. Dunn (1964) Kruskal-Wallis multiple comparison ( $p$-values adjusted with the BenjaminiHochberg method) was conducted. Post hoc test showed that the following pairs of treatments BAP1, BAP4; BAP2,BAP4; BAP1,Kn1; BAP2,Kn1; BAP2,Kn3; BAP1,Kn4; BAP2,Kn4 differed significantly as the $p$-values for the respective pairs were $<0.05$.

\section{Rooting}

Successful rooting of in vitro shoots prior to their establishment in soil is a prerequisite for any propagation method. Rooting of shoots is the most critical step also in the production of complete

Table 5. Regeneration of plantlets from somatic embryo

\begin{tabular}{crr}
\hline Day & No. of roots developed & No. of shoots developed* \\
\hline 7 & $3 \pm 1.56$ & $1.9 \pm 1.10$ \\
\hline 14 & $4.2 \pm 2.30$ & $3 \pm 1.56$ \\
\hline 21 & $6.3 \pm 2.06$ & $5.9 \pm 2.08$ \\
\hline 28 & $9.2 \pm 2.35$ & $7.8 \pm 1.81$ \\
\hline
\end{tabular}

*Data represents Mean \pm SE of 10 replicates

plants and their subsequent survival. Auxin added exogenously to in vitro generated shoots promotes root formation. Individual elongated healthy shoots were isolated and transferred to rooting media and rooting was highest (90\%) on fullstrength MS medium containing $1 \mathrm{mg} / \mathrm{l}$ IAA (Fig. 1 b). Statistical analysis showed that the different

Table 6. Measurement of SEM photoghaph

\begin{tabular}{lrr}
\hline \multicolumn{1}{c}{ Type of cell } & Length $(\mu \mathrm{m})$ & Width $(\mu \mathrm{m})$ \\
\hline Stomata in vivo leaf & 17.68 & 6.89 \\
\hline Stomata in vitro leaf & 23.77 & 8.18 \\
\hline Organogenic callus & 2884.23 & 2636.53 \\
\hline Embryogenic callus & 1552.69 & 2018.25 \\
\hline Globular stage & 13.58 & 13.71 \\
\hline Heart shaped stage & 4.09 & 4.47 \\
\hline Torpedo stage & 303.76 & 294.69 \\
\hline Bipolar stage & 39.24 & 31.01 \\
\hline
\end{tabular}

IAA concentrations used here, differed significantly among themselves (Table 2).

Table 2. Response of different concentrations of IAA for root formation (after 30 days of culture)

\begin{tabular}{lcrr}
\hline $\begin{array}{l}\text { Growth } \\
\text { regulators } \\
(\mathrm{mg} / \mathrm{l})\end{array}$ & $\begin{array}{l}\text { \% of root } \\
\text { formation }\end{array}$ & $\begin{array}{l}\text { No of root } \\
\text { formation/ } \\
\text { shoot }\end{array}$ & \multicolumn{2}{l}{$\begin{array}{l}\text { Root length* } \\
(\mathrm{cm})\end{array}$} \\
\hline IAA 0.25 & 80 & $7-13$ & $1.45 \pm 0.07$ \\
\hline IAA 0.50 & 80 & $9-16$ & $1.95 \pm 0.08$ \\
\hline IAA 1.00 & 90 & $13-20$ & $2.50 \pm 0.06$ \\
\hline IAA 1.50 & 90 & $7-11$ & $2.14 \pm 0.05$ \\
\hline IAA 2.00 & 80 & $5-11$ & $2.10 \pm 0.05$ \\
\hline
\end{tabular}

*Data represents Mean \pm SE of 10 replicates.

Note: To test if the growth regulators for root (different concentrations of IAA) differ significantly among themselves. HO: The growth regulators for root formation do not differ significantly among themselves, H1: The growth regulators differ significantly among themselves. One way ANOVA was conducted and the p-value was $<0.05$ therefore we rejected $\mathrm{HO}$ and concluded that the growth regulators (different concen-tration of IAA) differed significantly among them- selves. After Post-hoc test (Tukey multiple comparisons of means) it was concluded that Growth regulator pairs IAA 1.0, IAA 0.25; IAA 1.50,IAA0.50; IAA2.00,IAA0.05; IAA 1.50,IAA1.0; IAA2.0,IAA1.0 differed significantly (the respective $p$-values were $<0.05$ ).

\section{Acclimatization}

The transfer of plantlets from in vitro to ex vitro conditions is a very important step in the 
structural and physiological adaptation of plants; this is the beginning of the autotrophic life of plants. Micropropagated plants require their successful acclimatization and subsequent transfer to the field. The survival rate of the plants in field conditions was recorded as $70 \%$.

Table 3. Frequency of organogenic callus induction (after 35 days of culture)

\begin{tabular}{lrl}
\hline Medium & Frequency & Callus morphology \\
\hline 2,4-D $1 \mathrm{mg} / \mathrm{l}$ & 86.66 & $\begin{array}{l}\text { Thick compact yellow } \\
\text { callus }\end{array}$ \\
\hline 2,4-D $2 \mathrm{mg} / \mathrm{l}$ & 33.33 & Yellowish-white callus \\
\hline BAP $5 \mathrm{mg} / \mathrm{l}$ & 66.66 & Thick green callus \\
\hline
\end{tabular}

\section{Induction of callus}

Very little callus growth was seen in internode and node explants as compared to leaf explant. The calli were green to light yellowish in color with soft structures. After 10 days of culture the first swelling response for callus was observed in 2,4-D (1 mg/ l). In 2,4-D (2 mg/ l), the response for callus induction was seen after 17 days and in BAP $(5 \mathrm{mg} / \mathrm{l})$ the response was seen after 50 days of culture (Fig. 2 a). Higher concentration of 2,4-D $(>2 \mathrm{mg} / \mathrm{l})$ caused blackening of callus and when we used $<5$ $\mathrm{mg} / \mathrm{l}$ BAP, no callus formation was achieved. Callusing started at the cut ends of the explants after 10-17 days of culture in case of MS Basal media with 2,4-D 1mg/ 1 and 2,4-D $2 \mathrm{mg} / \mathrm{l}$. After 60 days of culture callus induction and vigorous growth were obtained in case of MS Basal media supplemented with BAP $5 \mathrm{mg} / \mathrm{l}$. Hence, it can be concluded that BAP $5 \mathrm{mg} / \mathrm{l}$ needs more time to initiate callus induction. The frequency of callus formation was highest when $1 \mathrm{mg} / \mathrm{l}$ 2,4-D was used $(86.66 \%)$ (Table 3). Influence of organic supplements on production of shoot and callus biomass was found in other plant like Centella asiatica (17).

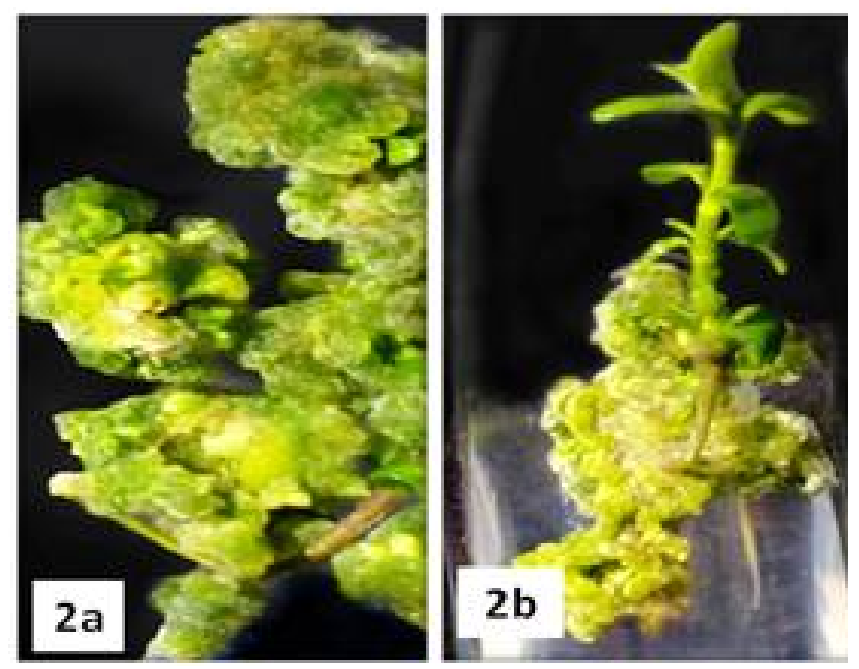

Fig. 2. a. Organogenic callus, b. Plantlet regeneration from organogenic callus $(\mathrm{ca} \times 2)$

\section{Organogenesis}

Plantlets formation was observed after 15 days of culture when intermodal and leaf callus were transferred to MS basal media (Fig. 2 b). As hormone free media was responsible for both shoot and root formation thus this protocol for regeneration from callus was much more cost effective. This protocol for regeneration from callus was much more cost effective.

\section{Somatic Embryo induction and maturation}

The success of micropropagation through somatic embryogenesis relies on somatic embryo induction and maturation and conversion of embryos to plantlets. Somatic embryo development was observed in the callus growing in the 2,4-D $1 \mathrm{mg} / \mathrm{l}$ followed by their respective transfer in basal media. The different developmental changes were seen (Fig. 3 a-e). After 7 days of induction about 1015/ culture tube globular (embryo) structure were observed per culture tube (Table 4). All the stages of somatic embryo development were obtained simultaneously. Somatic embryos were observed on the third subculture itself (i.e., between 80 and 90 days from the inoculation of explant) subsequent transfer facilitated development of large numbers of somatic embryos. There is other report which also inferred that withdrawal of auxin produced embryos faster than transferred to another media (18). Globular stage was characterized by small, globose or spherical; globular structure; pale yellow in colour (Fig. 3 a) followed by heart shaped stage which was a three lobed structure with a central depression; pale yellow in colour (Fig. 3 b). In torpedo stage the structure resembles an elongated heart; large and pale yellow in colour (Fig. 3 c) and further elongation of the torpedo shape stage (Fig. $3 \mathrm{~d}$ ) formed bipolar structure with defined root and shoot meristems that gave rise to a complete plant within a short span of time (Fig. 3 e).

\section{Somatic Embryo to Plantlet formation}

Shoot and root developments started after 7 days of culture and proper plantlets started developing after 21 days of culture in MS media supplemented with $\mathrm{Kn} 0.2 \mathrm{mg} / \mathrm{l}$. Individual embryos were loosely arranged with the explants and when the embryos were transferred to the media containing $\mathrm{Kn}$ $0.2 \mathrm{mg} / \mathrm{l}$, shoots were developed after 15 days followed by rooting (Table 5). So, satisfactory embryo germination was not observed until cytokinin was added. There are also records of using cytokinin for plantlet regeneration from embryogenic calli (Fig. 3 e). The stress regulated genes are induced during embryo maturation and germination and thus certain changes may occur. It is reported that growth regulators significantly influenced the frequency of somatic embryogenesis and plant regeneration (19). 

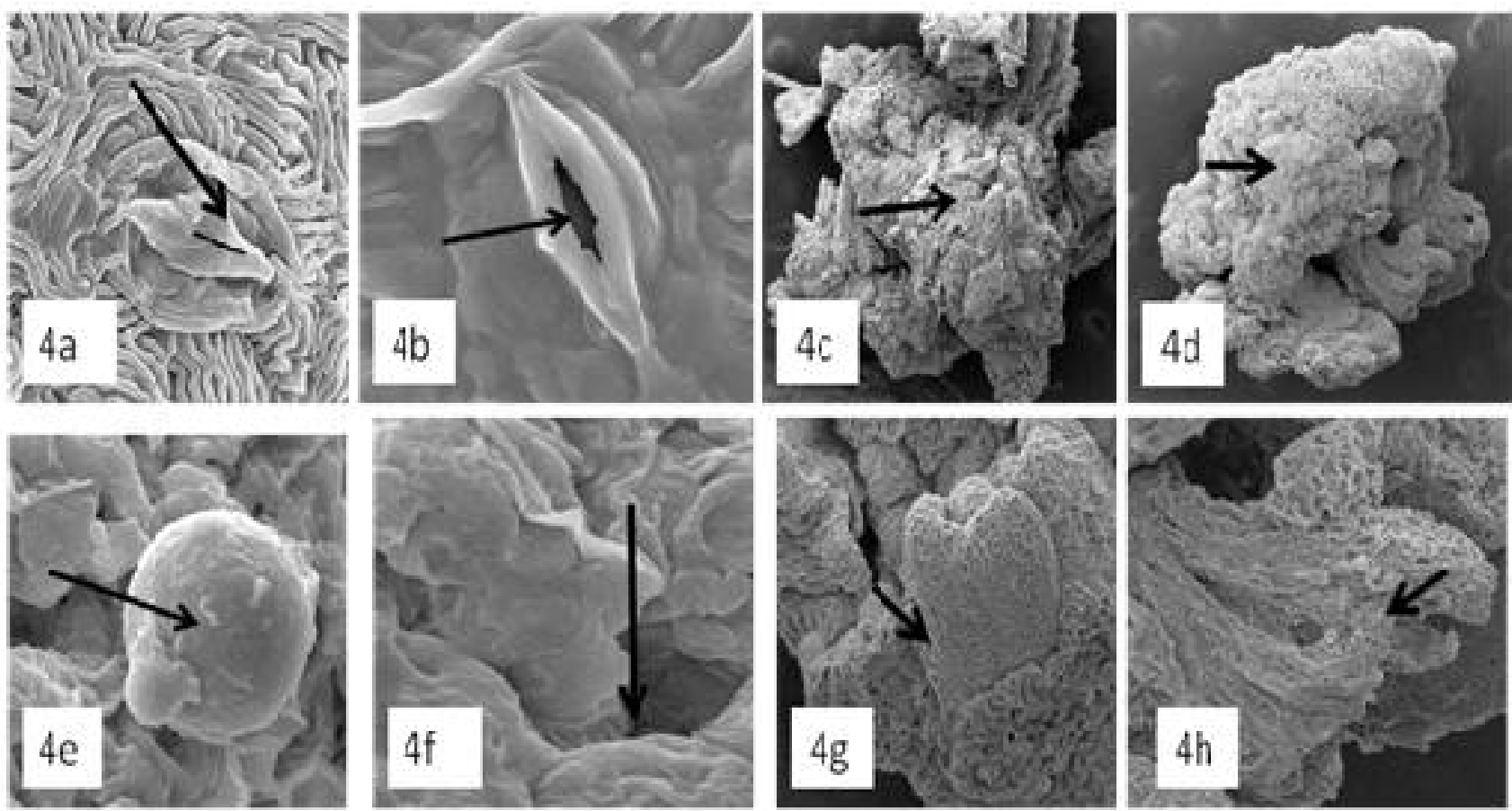

Fig. 4 a-h. Photograph from SEM analysis a. stomata in vivo leaf, b. stomata of in vitro leaf, c. organogenic callus, d. embryogenic callus, e. globular stage of somatic embryogenesis, $\mathbf{f}$. heart shaped stage of somatic embryogenesis, $\mathbf{g}$. Torpedo stage of somatic embryogenesis, $\mathbf{h}$. bipolar stage of somatic embryogenesis (ca $\times 92)$
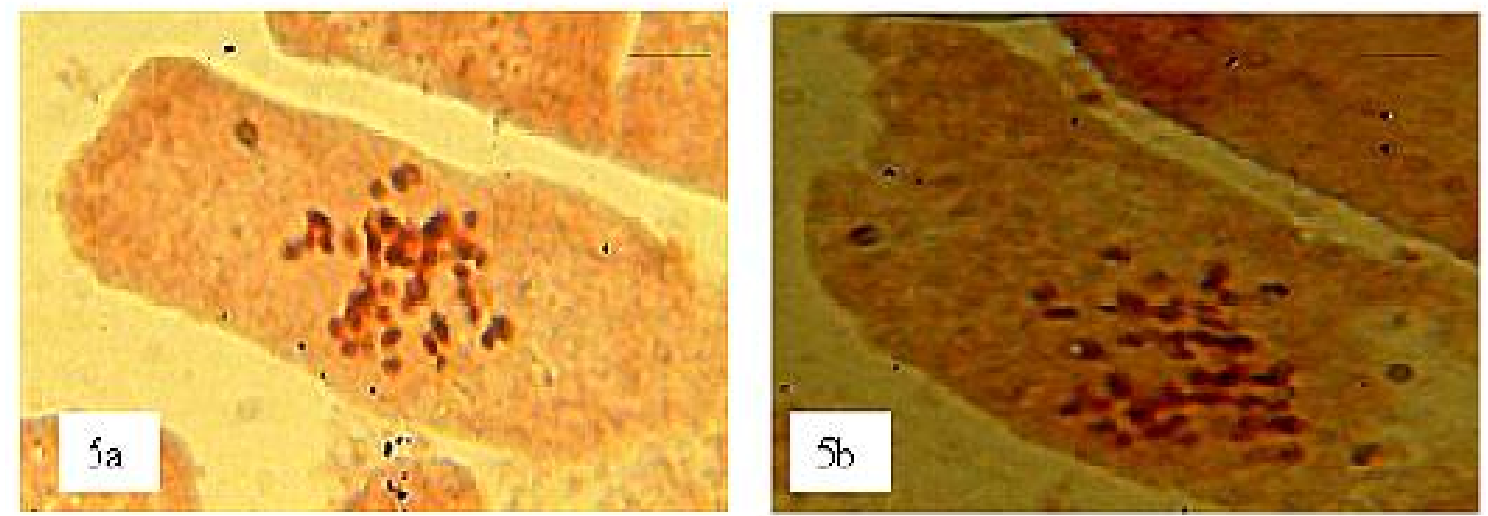

Fig. 5 a-b. Photographs of somatic metaphase plate a. In vivo plant, b. In vitro plant (ca $\times 1790$, bar= $5 \mu \mathrm{m})$
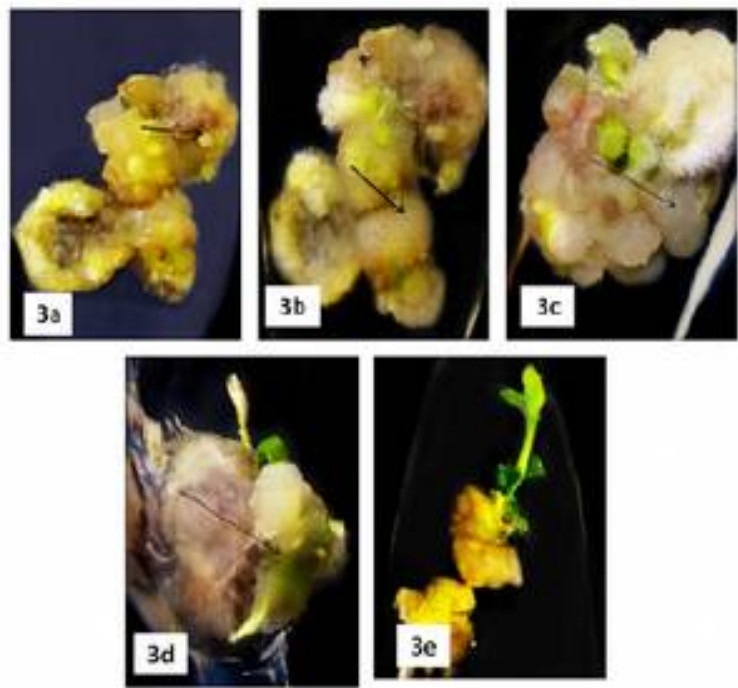

Fig. 3 a-e. Stages of somatic embryogenesis a. globular, b. heart shaped, c. torpedo, d. bipolar, e. plantlet formation $(\mathrm{ca} \times 1.5)$

\section{SEM analysis}

The size of stomata was compared using Scanning Electron Microscope (SEM) and the measurements were represented in (Table 6). Size of stomata did not very much in in vivo and in vitro plant. Different measurements of organogenic callus, embryogenic callus, different stages of somatic embryo development were represented in Table 6 (Fig. 4 a-h). SEM analysis was helpful for accurate measurement and exact structure determination which were very difficult from normal photographs. The exact structure of different stages of somatic embryogenesis can be visualized using SEM. The structure stomata and differences in pore size in vitro and in vivo leaf can be measured accurately with the help of SEM.

\section{Determination of chromosomal stability}

The stability was determined through chromosome analysis. Somatic chromosome 
number remains the same in in vivo $(2 \mathrm{n}=64$ chromosomes) and in vitro plantlets. So, at chromosome level stability was maintained (Fig. 5 a-b).

\section{Conclusion}

This research was undertaken to establish an efficient protocol for mass propagation of Bacopa from apical and axillary buds and conservation in natural habitats. Results showed that micropropagation, callus induction, somatic embryo induction and maturation were influenced by type and concentration of hormone. Murashige and Skoog (MS) basal medium containing $2 \mathrm{mg} / \mathrm{l}$ BAP was the best for shoot proliferation and the use of both apical and axillary bud was beneficial for clonal propagation. Elongated shoots were successfully rooted in MS basal supplemented with IAA $1.00 \mathrm{mg} / \mathrm{l}$. Somatic chromosome number remains the same in in vitro $(2 \mathrm{n}=64$ chromosomes $)$ and in vivo roots which revealed the chromosomal stability of regenerates. Regenerates after proper acclimatization were transferred to an ex vitro environment with $70 \%$ survival rate and no phenotypic changes was detected in comparison to in vivo plants of Bacopa. From the above study, it was concluded that leaves were best explant for callus induction of Bacopa. The effect of source and plant growth regulators on callus induction of Bacopa was explored here. We generally found that auxin is suitable for callus induction but in this study the highest amount of organogenic callus developed in MS medium supplemented with BAP $5 \mathrm{mg} / \mathrm{l}$, so this can be a new report for callus induction using cytokinin. A plant regeneration system was established in vitro from embryogenic callus. Somatic embryogenesis was influenced by the presence and absence of auxin hormone for embryo induction and maturation. Somatic embryo induction was best influenced in the presence of 2,4-D $1 \mathrm{mg} / \mathrm{l}$, but for subsequent embryo maturation hormone free MS Basal media was the beneficial. So in Bacopa tissue culture, morphogenetic response depends on plant growth regulators. Thus, our result on in vitro culture and somatic embryogenesis showed the considerable importance for large scale propagation. These protocols described in the present study were reproducible and can be used in future for further developments of the crop and may be applicable for other economically plants as well. The present study on callus induction and regeneration of Bacopa monnieri may help conservation of the species and possibly will lead to the production of secondary metabolites and extraction of active compounds from callus sources.

\section{Author's contribution}

DS has done Somatic Embryogenesis, SEM analysis, chromosome analysis, data analysis and prepared the content of the manuscript. BM has done collection of literature, identification and characterization of the plant. DR collected plants and subsequently established the culture followed by shoot bud multiplication, root induction, organogenic callus induction and acclimatization. DR also provided inputs and supervised the work.

\section{Acknowledgements}

This work was financially supported by the DBT and PG Department of Botany, lady Brabourne College. For SEM analysis authors also gratefully acknowledge the instrumental facilities provided by technician of Saltlake Campus, University of Calcutta. The authors like to thank Dr. Saswati Laha, Department of Botany, Bethune College to give immense support to this work including useful suggestions given by her in the field of collection of material and organogenesis part. We are grateful to Dr. Debabrata Maity, Department of Botany, University of Calcutta for plant identification and suggestions. We would sincerely thank Dr. Snigdha Pain, Consultant, Sankhya Analytical Research Pvt. Ltd., for statistical analysis and Dr. Sandip More, Visiting Scientist, GSI, for his cooperation in SEM analysis. We are also thankful to Dr. Suchita Sinha, Head, Department of Botany, Lady Brabourne College for her constant encouragement.

\section{References}

1. Lansdown Rv, Knees SG, Patzelt A. 2013. Bacopa monnieri. The IUCN Red list of Threatened Species 2013: $\quad$ e. $\quad$ T164168A17722668. https://doi.org/10.2305/IUCN.UK.2013-1

2. Ahmad RU. 1993. Medicinal plants used in ISM - their procurement, cultivation, regeneration and import/export aspects: a report. In: Govil J.N., Singh V.K., Hashmi S. (eds) Medicinal Plants: New Vistas of Research (Part 1) Today \& Tomorrow Printers and Publishers, New Delhi, pp. 221-25.

3. Khan AV, Ahmed QU, Shukla I, Khan AA. Antibacterial efficacy of Bacopa monnieri leaf extracts against pathogenic bacteria. Asian Biomedicine. 2010; 4: 65155. https://doi.org/10.2478/abm-2010-0084

4. Basu NK, Walia. The chemical investigations of the leaves of Herpestis monniera. Indian J. Pharm. 1994; 4:84-5.

5. Mohapatra HP, Rath SP. In vitro studies of Bacopa monnieri: An important medicinal plant with reference to its biochemical variations. Indian J. Exp. Biol. 2005; 43:373-6.

6. Mahato SB, Garai S, Chakravarty AK. Bacopasaponins E and F: Two jujubogenin bisdesmosides from Bacopa monnieri. Phytochemistry. 2000; 53:711-14. https://doi.org/10.1016/s0031-9422(99)00384-2

7. Rahman LU, Verma PC, Singh D, Gupta MM, Banerjee S. Bacoside production by suspension cultures of Bacopa monnieri (L.) Pennell. Biotechnol Lett. 2002; 24:1427-29.

8. Sehrawat AR, Sanjogta U, Anita P. In vitro culture and multiplication of Rauwolfia serpentina - a threatened medicinal plant. Crop Res. 2001; 22:68-71. 
9. Murashige T, Skoog F. A revised medium for rapid growth and bioassays with tobacco tissue cultures. Physiol. Plant. 1962; 15:473-97.

10. Behera S, Nayak N, Shasmita, Barik DP, Naik SK. An efficient micropropagation protocol of Bacopa monnieri (L.) Pennell through two-stage culture of nodal segments and ex vitro acclimatization. Journal of Applied Biology \& Biotechnology. 2015; 3:16-21. https://doi.org/10.7324/JABB.2015.3304

11. Tiwari V, Tiwari KN, Singh BD. Shoot regeneration and somatic embryogenesis from different explants of Brahmi [Bacopa monnieri (L.) Wettst.] Plant Cell Rep. 1998; 17:538-43. https://doi.org/10.1007/s002990050438

12. Tiwari V, Tiwari KN, Singh BD. Shoot bud regeneration from different explants of Bacopa monnieri (L.) Wettst. by trimithoprim and bavistin. Plant Cell Rep. 2006; 25:629-35. https://doi.org/10.1007/s00299-006-0126-5

13. Sharma S, Kamal B, Rathi N, Chauhan S, Jadon V, Vats $\mathrm{N}$, Gehlot A \& Arya S. In vitro rapid and mass multiplication of highly valuable medicinal plant Bacopa monnieri (L.) Wettst. Afr J Biotechnol. 2010; 9:8318-22. https://doi.org/10.5897/AJB09.878
14. Samanta D, Lahiri K, Mukhopadhyay MJ, Mukhopadhyay S. Karyomorphological analysis of different varieties of Tabernaemontana coronaria. Cytologia. $\quad 2015$; 80:67-73. https://doi.org/10.1508/cytologia.80.67

15. Srivastava N, Rajani M. Multiple shoot regeneration and tissue culture studies on Bacopa monnieri (L.) Pennell. Plant Cell Reports. 1999; 18:919-23. https://doi.org/10.1007/s002990050684

16. Banerjee M, Shrivastava S. An improved protocol for in vitro multiplication of Bacopa monnieri (L). World J Microbiol Biotechnol. 2008; 24:1355-59. https://doi.org/10.1007/s11274-007-9612-3

17. Patra A, Rai B, Rout GR, Das P. Successful regeneration from callus cultures of Centella asiatica (Linn.) Urban. Plant Growth Regulation. 1998; 24:13-6.

18. White PR. 1943. A Handbook of Plant Tissue Culture. The Jaques Cattell Press, Lancaster, Penn.

19. Narayanaswamy S. 1994. Plant cell and tissue culture. Tata McGraw Hill. New Delhi. 